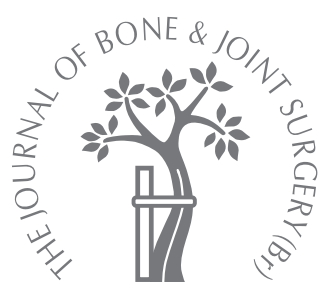
R. Bogner,
C. Hübner,
N. Matis,
A. Auffarth,
S. Lederer,
H. Resch

From the University Hospital of Salzburg, Salzburg, Austria

\title{
Minimally-invasive treatment of three- and four-part fractures of the proximal humerus in elderly patients
}

The surgical treatment of three- and four-part fractures of the proximal humerus in osteoporotic bone is difficult and there is no consensus as to which technique leads to the best outcome in elderly patients. Between 1998 and 2004 we treated 76 patients aged over 70 years with three- or four-part fractures by percutaneous reduction and internal fixation using the Humerusblock.

A displacement of the tuberosity of $>5 \mathrm{~mm}$ and an angulation of $>30^{\circ}$ of the head fragment were the indications for surgery.

Of the patients 50 (51 fractures) were available for follow-up after a mean of $\mathbf{3 3 . 8}$ months (5.8 to 81). The absolute, age-related and side-related Constant scores were recorded. Of the 51 fractures, 46 (90.2\%) healed primarily. Re-displacement of fragments or migration of Kirschner wires was seen in five cases. Necrosis of the humeral head developed in four patients. In three patients a secondary arthroplasty had to be performed, in two because of re-displacement and in one for necrosis of the head. There was one case of deep infection which required a further operation and one of delayed healing.

The mean Constant score of the patients with a three-part fracture was $\mathbf{6 1 . 2}$ points (35 to 87 ) which was $\mathbf{8 4 . 9 \%}$ of the score for the non-injured arm. In four-part fractures it was 49.5 points ( 18 to 87 ) or $68.5 \%$ of the score for the non-injured arm.

The Humerusblock technique can provide a comfortable and mobile shoulder in elderly patients and is a satisfactory alternative to replacement and traditional techniques of internal fixation.

Fractures of the proximal humerus are common in the elderly. The overall prevalence is about 70 per 100000 population/year, representing about $5 \%$ of all fractures. ${ }^{1-3}$ The prevalence rises to 405 per 100000 population/ year over the age of 70 years. ${ }^{4-6}$

In elderly patients, restoration of muscle power to the injured arm is not the prime objective. The main requirement is to handle activities of daily living which do not need much strength, but require a reasonable range of movement. There is a particular need for sufficient external rotation for washing and combing hair and enough internal rotation for eating and for personal hygiene.

In these patients, pre-existing osteopenia or osteoporosis can lead to highly comminuted fractures which are difficult to treat., 1,-12 Non-operative management is associated with poor results. ${ }^{11,13}$

Whilst arthroplasty in these patients gives good relief from pain, ${ }^{14}$ the outcome in terms of function is often poor. ${ }^{15-17}$ Following arthroplasty after fracture about $50 \%$ of primarily-reduced tuberosities are secondarily resorbed. ${ }^{18-20}$ This in turn impairs post-operative function because of cranial migration of the prosthesis. ${ }^{21}$ Because of these unsatisfactory results, ${ }^{7,21,22}$ open reduction and stabilisation of such fractures has become more common. However, a major problem of open reduction is that it carries the risk of further deterioration in the blood supply to the fracture fragments.

In an attempt to address these problems, many different techniques such as cerclage wires, T-plates, intramedullary nails, tubular plates and arthroplasty have been used. ${ }^{8-10,14,23-33}$ However, osteosynthesis is often compromised by pre-existing osteopenia. ${ }^{12,34}$ Implants which are too rigid may lead to delayed healing or nonunion by preventing dynamic bone contact or may simply cut out of the osteopenic bone. ${ }^{35}$ In elderly patients flexible implants which can minimise the load of the implantbone interface have shown advantages in biomechanical tests. ${ }^{36} \mathrm{~A}$ dynamic fixation construct is important in the elderly who will also benefit from early restoration of function. ${ }^{36}$ 


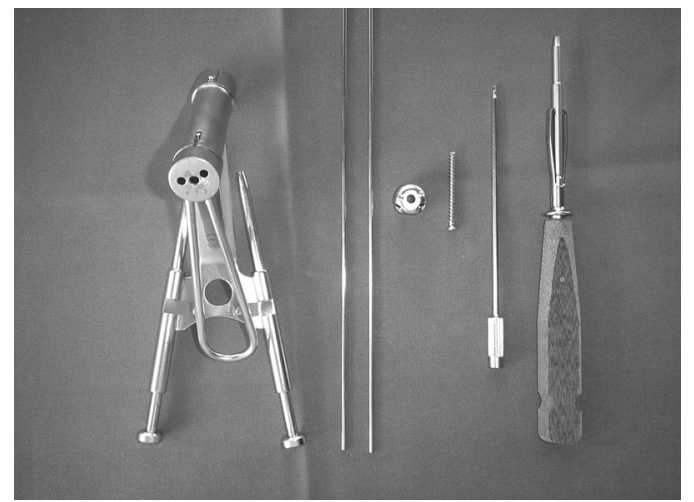

Fig. 1a

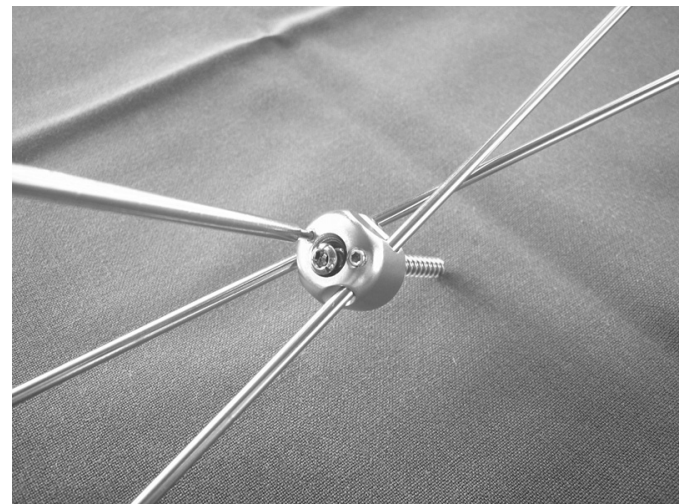

Fig. 1b

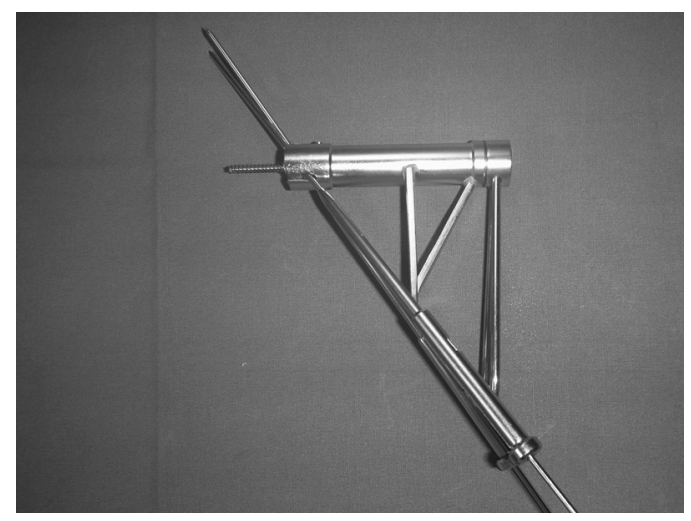

Fig. 1c

Photographs showing the Humerusblock.

However, the ideal type of fixation in such cases has not yet been established.

We present the results of percutaneous reduction and minimally-invasive fixation of three- and four-part fractures of the proximal humerus using the Humerusblock technique (Synthes, Oberdorf, Switzerland) in a group of patients aged 70 years or older.

\section{Patients and Methods}

Between 1998 and 2004, we treated 351 displaced fractures of the proximal humerus surgically. There were 16 fractures of the head which were treated by open reduction and fixation using blade plates and ten by a primary arthroplasty. The remaining 325 fractures were treated by percutaneous reduction and minimally invasive fixation using the Humerusblock technique. Tuberosities were reduced percutaneously and fixed by cannulated screws.

Subacromial impingement and marked limitation of movement are common complications of conservativelytreated three- or four-part fractures of the proximal humerus. ${ }^{37}$ In our experience this often requires surgical treatment. A displacement of the greater tuberosity of
$>5 \mathrm{~mm}$ or an angle of $\geq 30^{\circ}$ between the shaft and head fragment were indications for surgery.

From the 325 patients, we identified $76(23.4 \%)$ aged $\geq 70$ years with a three- or four-part fracture. There were 63 women and 13 men with a mean age of 79.6 years (70 to 96). The mean follow-up was for 33.8 months (5.8 to 81.0). The mechanism of injury had been a fall when walking in 74 patients and a bicycle accident in two. The mean time between the injury and surgery was 2.1 days (0 to 11 ).

Operative technique. The technique has been published previously. ${ }^{23-26,28,38-40}$ Briefly the device consists of a metal block which is fixed to the humeral shaft by a cannulated cortical screw. Two crossed Kirschner (K)-wires holding the head fragment are passed through the block at an angle of $45^{\circ}$ and are held in place by a locking screw (Fig. 1).

The patient is placed in the beach-chair position and an image intensifier is used. A skin incision $3 \mathrm{~cm}$ in length is made on the lateral side of the upper arm, about $4 \mathrm{~cm}$ to $5 \mathrm{~cm}$ below the fracture. The deltoid muscle is split and the block fixed to the humeral shaft by a cannulated cortical screw. This screw is not initially completely tightened to allow varus or valgus adjustment of the block. With the 
Table I. Mean (range) absolute Constant scores for both groups

\begin{tabular}{llr}
\hline Constant score & Three-part $(\mathbf{n}=\mathbf{3 2})$ & Four-part $(\mathbf{n}=\mathbf{1 6})$ \\
\hline Pain & $14(5$ to 15$)$ & $12(5$ to 15$)$ \\
Range of movement & $27(6$ to 40$)$ & $21(4$ to 40$)$ \\
Power & $6(0$ to 12$)$ & $5(0$ to 12$)$ \\
Activities of daily living & $14(2$ to 20$)$ & $12(3$ to 20$)$ \\
Total & $61(35$ to 87$)$ & $50(18$ to 87$)$ \\
\hline
\end{tabular}

arm in neutral rotation the block is adjusted in the anteroposterior (AP) view so that the centre between both K-wires aims at the lateral humeral epicondyle. Directed by guiding sleeves, both $2.2 \mathrm{~mm}$ K-wires are introduced just below the subcapital fracture.

In three-part fractures, the subcapital fracture is reduced percutaneously with the arm in adduction and internal rotation. In cases of excessive internal rotation of the head fragments, a bone hook is inserted through a separate stab incision for derotation. The greater tuberosity is then manipulated using a hook. When anatomically reduced, the $\mathrm{K}$-wires are passed through the humeral head to subchondral bone. If needed, one or more $2.7 \mathrm{~mm}$ titanium screws (Stryker Leibinger Micro Implants, Freiburg, Germany) are inserted to hold the greater tuberosity.

In valgus-type four-part fractures, an elevator is inserted between the fragments and the head raised to its anatomical position as indicated by the greater tuberosity. The reduced head is secured by both $2.2 \mathrm{~mm} \mathrm{~K}$-wires of the Humerusblock as described above. The greater tuberosity in most cases regains its anatomical position when the articular fragment is elevated. Next, two cannulated $2.7 \mathrm{~mm}$ screws, are inserted to hold the greater tuberosity, one directed superiorly into the articular segment close to the subchondral bone and the other in an inferior direction towards the medial cortex. The lesser tuberosity is also reduced and fixed as described above. Finally, both K-wires are locked inside the block, shortened and the wound closed.

After operation the arm is immobilised with a light bandage for three to four weeks. Depending on the degree of stability achieved, passive exercising in the scapular plane without rotating the arm is started on the first post-operative day. Active exercises are allowed at the start of the fourth week. After five to six weeks the metal is removed. In slim patients removal is possible under local anaesthesia.

The patients were assessed clinically and radiologically at follow-up. The function of the shoulder was evaluated using the score of Constant and Murley $^{41}$ and compared with the uninjured side. Pain was assessed on a visual analogue scale ranging from 0 to 15 points. The ability to perform activities of daily living was scored with a maximum of 20 points. ${ }^{41}$ Range of movement (maximum 40 points) was measured with a goniometer. Muscle strength (maximum 25 points) was determined by a spring-scale. Radiological examination included anteroposterior (AP) and axial views. In addition, the results were compared with age- and gender-matched normal values. Finally, patients were asked whether they were satisfied with the result.

\section{Results}

Of the 76 patients, 23 had died and three were lost to follow-up leaving 50 with 51 fractures available for review. Three patients had undergone revision to an endoprosthesis for avascular necrosis of the humeral head in one and secondary displacement of the fragments in two. A hemiarthroplasty was performed in all three patients and they were excluded from the analysis. Of the remaining 48 patients one had a bilateral fracture and another two had injuries or lesions of the other arm. Therefore, a relative Constant score was not applicable in these cases, although the absolute Constant score as well as the age- and gendermatched values were recorded. Of the 48 patients, $32 \mathrm{had}$ a three- and 16 a four-part fracture.

In the 32 with a three-part fracture the mean absolute Constant score at follow-up was 61.2 points ( 35 to 87 ). This was $84.9 \%$ of the score for the uninjured arm (mean 72.1 points (43 to 89)). Compared with age- and gender-matched normal values, this equated to $94.9 \%$ of the anticipated score.

In four-part fractures the mean absolute Constant score at follow-up was 49.5 points (18 to 87 ). This was $68.5 \%$ of the score for the uninjured arm (mean 72.3 points (56 to 91)). Compared with age- and gender-matched normal values, this equated to $75 \%$ of the anticipated score.

Of the 16 patients with four-part fractures, two also had an injury to the brachial plexus. The Constant score for these two shoulders was considerably lower at 29 and 38 points, respectively.

With regard to pain, patients with three-part fractures had a mean of 14 points ( 5 to 15 ). Of these, 30 had no or mild pain, one had moderate and another severe pain. Patients with four-part fractures had a mean of 12 points (5 to 15$)$. Of the 16 patients 14 had no or mild pain, one moderate and one severe pain. Of the four patients with moderate or severe pain, one had post-operative necrosis of the humeral head and the other three had previously sustained rotator-cuff tears (Table I).

The mean score for the range of movement was 27 points ( 6 to 40 ) in three-part and 21 points ( 4 to 40 ) in four-part fractures (Table I).

The mean flexion in three-part fractures was $127^{\circ}$ $\left(50^{\circ}\right.$ to $\left.175^{\circ}\right)$. The mean abduction was $122^{\circ}\left(50^{\circ}\right.$ to $\left.170^{\circ}\right)$ and the mean external rotation from the neutral arm position was $31^{\circ}\left(10^{\circ}\right.$ to $\left.45^{\circ}\right)$. In internal rotation 13 patients could reach the thoracic spine and 13 were only able to reach the sacroiliac joint or lumbar spine. The remaining six patients reached the buttock or lateral thigh.

In four-part fractures the mean flexion was $103^{\circ}$ $\left(50^{\circ}\right.$ to $\left.175^{\circ}\right)$. The mean abduction was $97^{\circ}\left(45^{\circ}\right.$ to $\left.170^{\circ}\right)$ and the mean external rotation from the neutral arm position was $23^{\circ}\left(0^{\circ}\right.$ to $\left.40^{\circ}\right)$. In internal rotation four patients could reach the thoracic spine and nine the sacroiliac joint or lumbar spine (Table II). Another three patients reached the buttock. 
Table II. Mean (range) range of movement for both groups

\begin{tabular}{lcccc}
\hline Direction & \multicolumn{2}{c}{ Three-part $(\mathbf{n}=\mathbf{3 2})$} & \multicolumn{2}{c}{ Four-part (n = 16) } \\
\hline Flexion $\left(^{\circ}\right)$ & 127 & $(50$ to 175$)$ & 103 & (50 to 175) \\
Abduction $\left(^{\circ}\right)$ & 122 & $(50$ to 170$)$ & 97 & $(45$ to 170$)$ \\
Internal rotation (points) & $5.9(0$ to 10$)$ & 4.9 & $(0$ to 10$)$ \\
External rotation $\left({ }^{\circ}\right)$ & 31 & $(10$ to 45$)$ & 23 & $(0$ to 40$)$ \\
\hline
\end{tabular}

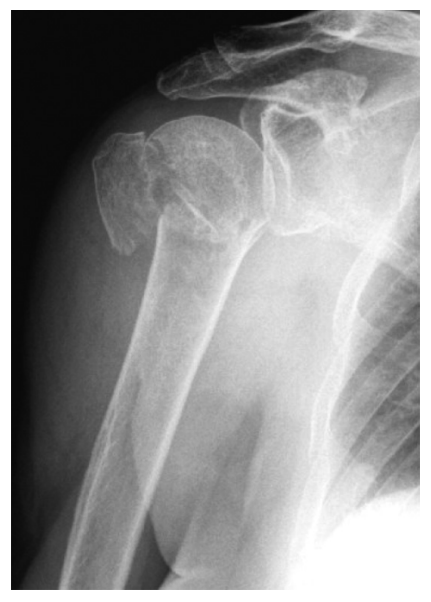

Fig. 2a

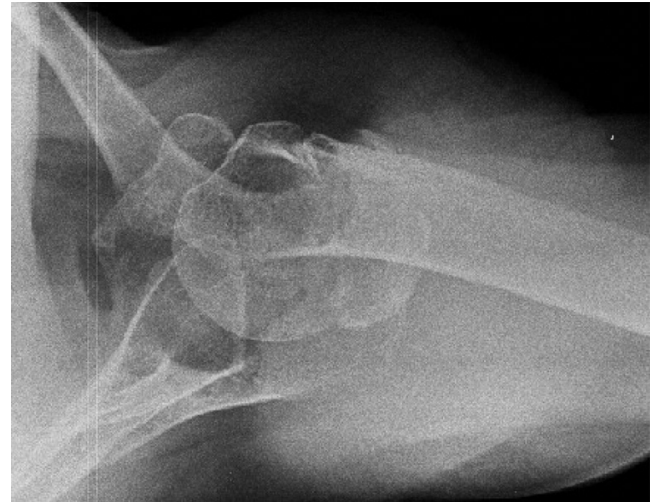

Fig. 2b

Anteroposterior (a) and axial (b) views of a three-part fracture of the proximal humerus in a 74-year-old woman.

All the patients with three-part fractures and $81.3 \%$ (13 patients) of those with four-part fractures were satisfied or very satisfied with the result (Figs 2 to 4 ).

Complications. A total of 46 fractures $(90.2 \%)$ healed primarily. Secondary displacement of fragments or migration of the K-wires was seen in five $(10.4 \%)$. In three of these revision surgery using the Humerusblock was carried out successfully. In the remaining two a hemiarthroplasty was performed. There was one case of deep infection and one of delayed wound healing.

Avascular necrosis of the humeral head developed in four patients $(7.8 \%)$ of whom three initially had a four-part fracture; three were satisfied with the outcome, and in one a hemiarthroplasty was performed. Out of the total of 51 fractures, three hemiarthoplasties $(5.9 \%)$ were performed secondary to the Humerusblock, two because of fragment dislocation and one because of avascular necrosis of the head of the humerus.

\section{Discussion}

Our findings showed that in comparison with other surgical methods good relief from pain and movement were achieved using the Humerusblock. One disadvantage of semi-rigid techniques of fixation has been the need for postoperative immobilisation of the arm. Because our procedure is performed percutaneously, there was minimal soft-tissue disruption and the shoulder could be mobilised early, as in non-operative treatment.

The technique preserves remaining periosteal bridges, which may represent the last link of perfusion to the articular fragment. Consequently, the incidence of necrosis of the humeral head was only $7.8 \%$ in our series, whereas rates of avascular necrosis of $14 \%$ to $35 \%$ have been reported following open reduction. ${ }^{42-44}$ The minimum follow-up was, however, too short for a definitive conclusion to be reached.

There were no cases of nonunion which may be related to the preservation of contact between the bone fragments throughout the fixation process. As the tips of the K-wires have to be placed just below the joint surface in order to grip the humeral head they can penetrate the articular cartilage and in these cases they have to be withdrawn before mobilisation is started. This additional intervention is a slight disadvantage of the technique, although it can be done under local anaesthesia.

Closed reduction in three- and especially four-part fractures is a technically-demanding procedure. Before using this technique the nature of the injury should be understood, the number and position of the fragments determined and the potential periosteal links between the fragments noted. In this respect, CT with three-dimensional reconstruction may be helpful. ${ }^{38}$ 


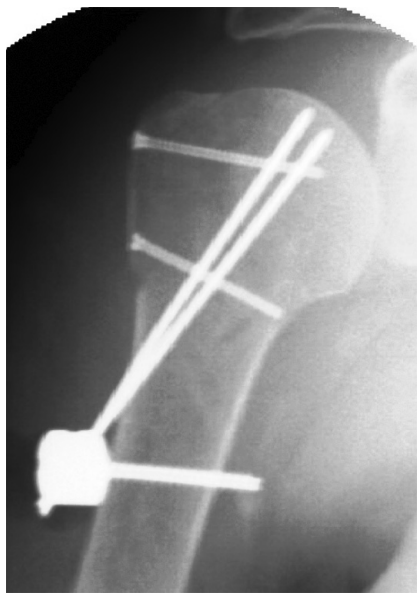

Fig. 3a

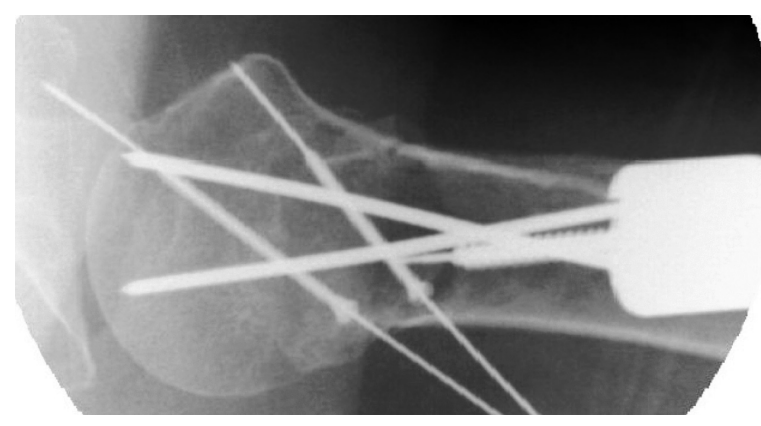

Fig. 3b

Anteroposterior (a) and axial (b) views after reduction and fixation with the Humerusblock and two cannulated screws in the patient shown in Figure 2.

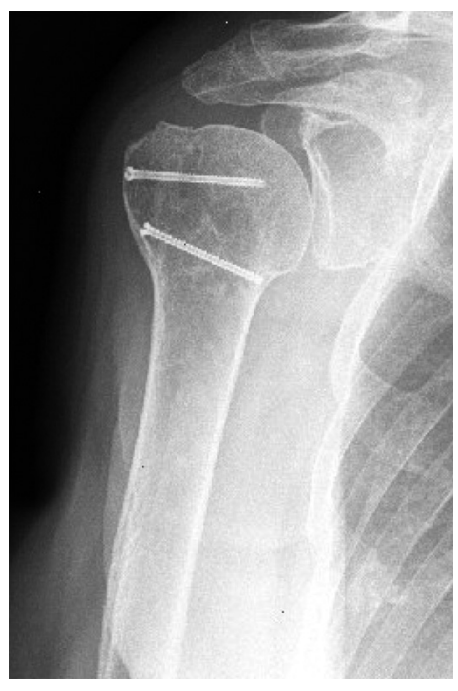

Fig. $4 \mathrm{a}$

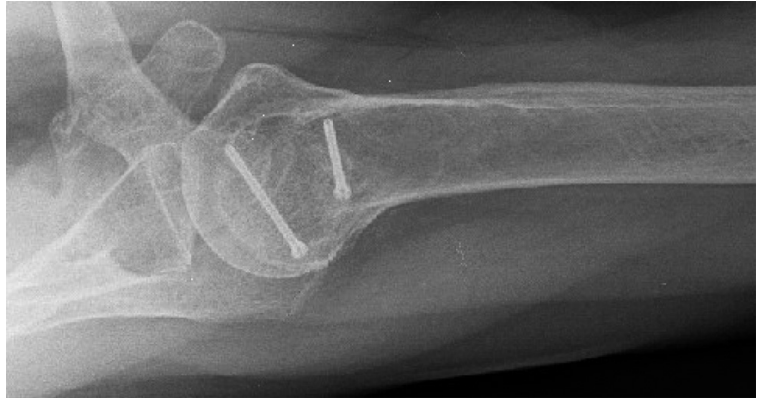

Fig. 4b

Anteroposterior (a) and axial (b) views of the same patient at follow-up at three years. The Humerusblock had been removed six weeks after operation.

Complications of arthroplasty for fractures of the proximal humerus include displacement, nonunion and malunion or resorption of the tuberosities, especially in osteoporotic bone. All of these cause limitation of movement. ${ }^{21,22,34,43,45}$ We observed avascular necrosis of the humeral head but not malunion of either the greater or lesser tuberosity. If a secondary arthroplasty is required an anatomical shoulder prosthesis can be used.

During the last few years the introduction of angle-stable plates has proved to be popular but stability of the implant does not necessarily lead to union of the fracture. In osteoporotic bone, fixed-angle screws can cut out and penetrate the joint. They may also increase bone resorption by preventing contact between the shaft and head fragments. ${ }^{35}$
Furthermore, open anatomical reconstruction and plating results in a higher rate of avascular necrosis ${ }^{29,43,46,47}$ than that seen when using the Humerusblock.

Percutaneous reduction and minimally-invasive fixation of subcapital humeral fractures using the Humerusblock technique gives good results with satisfactory relief from pain and range of movement.

\section{Supplementary material}

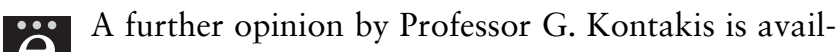
able with the electronic version of this article on our website at www.jbjs.org.uk

No benefits in any form have been received or will be received from a commercial party related directly or indirectly to the subject of this article. 


\section{References}

1. Court-Brown CM, Garg A, McQueen MM. The epidemiology of proximal humeral fractures. Acta Orthop Scand 2001;72:365-71.

2. Court-Brown CM, Caesar B. Epidemiology of adult fractures: a review. Injury 2006;37:691-7.

3. Helmy N, Hintermann B. New trends in the treatment of proximal humerus fractures. Clin Orthop 2006;442:100-8.

4. Bengner U, Johnell 0, Redlund-Johnell I. Changes in the incidence of fracture of the upper end of the humerus during a 30 -year period: a study of 2125 fractures. Clin Orthop 1988;231:179-82

5. Kannus P, Palvanen M, Niemi S, et al. Osteoporotic fractures of the proximal humerus in elderly Finnish persons: sharp increase in 1970-1998 and alarming projections for the new millennium. Acta Orthop Scand 2000;71:465-70.

6. Lind T, Krøner K, Jensen J. The epidemiology of fractures of the proximal humerus. Arch Orthop Trauma Surg 1989;108:285-7.

7. Bosch U, Skutek M, Fremerey RW, Tscherne H. Outcome after primary and secondary hemiarthroplasty in elderly patients with fractures of the proximal humerus. J Shoulder Elbow Surg 1998; 7:479-84.

8. Hintermann B, Trouillier HH, Schafer D. Rigid internal fixation of fractures of the proximal humerus in older patients. J Bone Joint Surg [Br] 2000;82-B:1107-12.

9. Kostler W, Strohm PC, Sudkamp NP. Proximal humerus fracture in advanced age: treatment with fixed angle plate osteosynthesis. Chirurg 2003;74:985-9 (in German).

10. Koukakis A, Apostolou CD, Taneja T, Korres DS, Amini A. Fixation of proximal humerus fractures using the PHILOS plate: early experience. Clin Orthop 2006;442:115-20.

11. Lill H, Josten C. Conservative or operative treatment of numeral head fractures in the elderly? Chirurg 2001;72:1224-34 (in German).

12. Zyto K, Ahrengart L, Sperber A, Tornkvist H. Treatment of displaced proximal humeral fractures in elderly patients. J Bone Joint Surg [Br] 1997;79-B:412-17.

13. Misra A, Kapur R, Maffulli N. Complex proximal humeral fractures in adults: a systematic review of management. Injury 2001;32:363-72.

14. Bufquin T, Hersan A, Hubert L, Massin P. Reverse shoulder arthroplasty for the treatment of three- and four-part fractures of the proximal humerus in the elderly: a prospective review of 43 cases with a short-term follow-up. J Bone Joint Surg [Br] 2007;89-B:516-20.

15. Ko JY, Yamamoto R. Surgical treatment of complex fracture of the proximal humerus. Clin Orthop 1996;327:225-37.

16. Rüter A. Indication and technique for shoulder endoprostheses in fractures. Chirurg 2001;72:1246-52 (in German).

17. Goldman RT, Koval KJ, Cuomo F, Gallagher MA, Zuckerman JD. Functional outcome after humeral head replacement for acute three- and four-part proximal humeral fractures. J Shoulder Elbow Surg 1995;4:81-6.

18. Boileau P, Krishnan SG, Tinsi L, et al. Tuberosity malposition and migration: reasons for poor outcomes after hemiarthroplasty for displaced fractures of the proximal humerus. Shoulder Elbow Surg 2002;11:401-12.

19. Prakash V, McGurty DW, Dent JA. Hemiarthroplasty for severe fractures of the proximal humerus. J Shoulder Elbow Surg 2002;11:428-30.

20. Loew M, Heitkemper S, Parsch D, Schneider S, Rickert M. Influence of the design of the prosthesis on the outcome after hemiarthroplasty of the shoulder in displaced fractures at the head of the humerus. J Bone Joint Surg [Br] 2006;88-B:345-50.

21. Kralinger F, Schwaiger $\mathbf{R}$, Wambacher $\mathbf{M}$, et al. Outcome after primary hemiarthroplasty for fracture of the head of the humerus: a retrospective multicentre study of 167 patients. J Bone Joint Surg [Br] 2004;86-B:217-19.

22. Zyto K, Wallace WA, Frostick SP, Preston BJ. Outcome after hemiarthroplasty for three- and four-part fractures of the proximal humerus. J Shoulder Elbow Surg 1998;7:85-9.

23. Chen CY, Chao EK, Tu YK, Ueng SW, Shih CH. Closed management and percutaneous fixation of unstable proximal humerus fractures. J Trauma 1998;45:1039-45.

24. Herscovici D Jr, Saunders DT, Johnson MP, Sanders R, DiPasquale T. Percutaneous fixation of proximal humeral fractures. Clin Orthop 2000;375:97-104.
25. Hessmann MH, Rommens PM. Osteosynthesis techniques in proximal humeral fractures. Chirurg 2001;72:1235-45 (in German).

26. Le Bellec $Y$, Masmejean E, Cottias $P$, Alnot JY, Huten D. Internal fixation of proximal humerus fracture by "palm tree" pinning. Rev Chir Orthop Reparatrice Appar Mot 2002;88:342-48 (in French).

27. Plecko M, Kraus A. Internal fixation of proximal humerus fractures using the locking proximal humerus plate. Oper Orthop Traumatol 2005;17:25-50.

28. Resch H, Povacz P, Frohlich R, Wambacher M. Percutaneous fixation of threeand four-part fractures of the proximal humerus. J Bone Joint Surg [Br] 1997;79B:295-300.

29. Kralinger F, Irenberger A, Lechner C, et al. Comparison of open versus percutaneous treatment for humeral head fracture. Unfallchirurg 2006;109:406-10 (in German).

30. Nho SJ, Brophy RH, Barker JU, Cornell CN, MacGillivray JD. Management of proximal humeral fractures based on current literature. J Bone Joint Surg [Am] 2007;89-A(Suppl 3):44-58

31. Röderer G, Abouelsoud M, Gebhard F, Böckers TM, Kinzl L. Minimally invasive application of the non-contact-bridging (NCB) plate to the proximal humerus: an anatomical study. J Orthop Trauma 2007;21:621-7.

32. Sosna A, Pokorny D, Hromádka R, et al. A new technique for reconstruction of the proximal humerus after three- and four-part fractures. J Bone Joint Surg [Br] 2008;90B:194-9.

33. Moonot $\mathbf{P}$, Ashwood N, Hamlet $\mathbf{M}$. Early results for treatment of three- and fourpart fractures of the proximal humerus using the PHILOS plate system. J Bone Joint Surg [Br] 2007;89-B:1206-9.

34. Wambacher W, Golser K, Wischatta R, Sperner G. Outcome after primary prosthetic replacement following displaced fractures of the proximal humerus. Euro $\mathrm{J}$ Trauma 2001;E-Supplement 1/2001:118-23.

35. Sadowski C, Riand N, Stern R, Hoffmeyer P. Fixation of fractures of the proximal humerus with the PlantTan Humerus Fixator Plate: early experience with a new implant. J Shoulder Elbow Surg 2003;12:148-51.

36. Lill H, Hepp P, Korner J, et al. Proximal humeral fractures: how stiff should an implant be?: a comparative mechanical study with new implants in human specimens. Arch Orthop Trauma Surg 2003;123:74-81.

37. Bono CM, Renard R, Levine RG, Levy AS. Effect of displacement of fractures of the greater tuberosity on the mechanics of the shoulder. J Bone Joint Surg $[\mathrm{Br}]$ 2001;83-B:1056-62.

38. Resch H, Hubner C, Schwaiger R. Minimally invasive reduction and osteosynthesis of articular fractures of the humeral head. Injury 2001;32(Suppl 1):25-32.

39. Soete PJ, Clayson PE, Costenoble VH. Transitory percutaneous pinning in fractures of the proximal humerus. J Shoulder Elbow Surg 1999;8:569-73.

40. Resch H, Aschauer E, Povacz P, Ritter E. Closed reduction and fixation of articular fractures of the humeral head. Techniques in Shoulder \& Elbow Surgery 2000;3:154-62.

41. Constant CR, Murley AHG. A clinical method of functional assessment of the shoulder. J Bone Joint Surg [Br] 1986;68-B:667.

42. Hawkins RJ, Bell RH, Gurr K. The three-part fracture of the proximal part of the humerus. J Bone Joint Surg [Am] 1986;68-A:1410-14.

43. Savoie FH, Geissler WB, Vandergriend RA. Open reduction and internal fixation of three-part fractures of the proximal humerus. Orthopedics 1989;12:65-70.

44. Gerber C, Werner CM, Vienne P. Internal fixation of complex fractures of the proximal humerus. J Bone Joint Surg [Br] 2004;86-B:848-55.

45. Plausinis D, Kwon YW, Zuckerman JD. Complications of humeral head replacement for proximal humeral fractures. Instr Course Lect 2005;54:371-80.

46. Damanakis K, Schaal O, Mann J, Muller KH. Modified treatment concept in fractures of the humeral head in elderly patients. Unfallchirurg 1996;99:561-8 (in German).

47. Kuner EH, Siebler G. Dislocation fractures of the proximal humerus: results following surgical treatment: a follow-up study of 167 cases. Unfallchirurg 1987;13:64-71 (in German). 